Wright State University

CORE Scholar

3-1-2003

\title{
Plasma-Etching-Enhanced Deep Centers in n-GaN Grown by Metalorganic Chemical-Vapor Deposition
}

\author{
Z-Q. Fang \\ David C. Look \\ Wright State University - Main Campus, david.look@wright.edu \\ X. L. Wang \\ J. Han \\ F. A. Khan
}

See next page for additional authors

Follow this and additional works at: https://corescholar.libraries.wright.edu/physics

Part of the Physics Commons

\section{Repository Citation}

Fang, Z., Look, D. C., Wang, X. L., Han, J., Khan, F. A., \& Adesida, I. (2003). Plasma-Etching-Enhanced Deep Centers in n-GaN Grown by Metalorganic Chemical-Vapor Deposition. Applied Physics Letters, 82 (10), 1562-1564.

https://corescholar.libraries.wright.edu/physics/82

This Article is brought to you for free and open access by the Physics at CORE Scholar. It has been accepted for inclusion in Physics Faculty Publications by an authorized administrator of CORE Scholar. For more information, please contact library-corescholar@wright.edu. 
Authors

Z-Q. Fang, David C. Look, X. L. Wang, J. Han, F. A. Khan, and I. Adesida

This article is available at CORE Scholar: https://corescholar.libraries.wright.edu/physics/82 


\title{
Plasma-etching-enhanced deep centers in $n$-GaN grown by metalorganic chemical-vapor deposition
}

\author{
Z.-Q. Fang ${ }^{\text {a) }}$ and D. C. Look \\ Semiconductor Research Center, Wright State University, Dayton, Ohio 45435 \\ X.-L. Wang and Jung Han \\ Department of Electrical Engineering, Yale University, New Haven, Connecticut 06520
}

F. A. Khan and I. Adesida

Micro and Nanotechnology Laboratory and Department of Electrical and Computer Engineering, University of Illinois, Urbana, Illinois 61801

(Received 24 October 2002; accepted 20 January 2003)

\begin{abstract}
By using deep-level transient spectroscopy (DLTS), deep centers have been characterized in unintentionally doped $n$-GaN samples grown by metalorganic chemical-vapor deposition and subjected to inductively coupled plasma reactive ion etching. At least six DLTS traps exist in the control sample: $\mathrm{A}_{1}(\sim 0.90 \mathrm{eV}), \mathrm{A}_{x}(\sim 0.72 \mathrm{eV}), \mathrm{B}(0.61 \mathrm{eV}), \mathrm{C}_{1}(0.44 \mathrm{eV}), \mathrm{D}(0.25 \mathrm{eV})$, and $\mathrm{E}_{1}$ $(0.17 \mathrm{eV})$, with $\mathrm{B}$ dominant. Then, as the etching bias-voltage increases from -50 to $-150 \mathrm{~V}$, trap $D$ increases strongly and becomes dominant, while traps $A_{1}, C(0.34 \mathrm{eV})$, and $E_{1}$ increase at a slower rate. Trap B, on the other hand, is nearly unchanged. Previous electron-irradiation studies are consistent with the $\mathrm{E}_{1}$ traps being $\mathrm{N}$-vacancy related. It is likely that the $\mathrm{D}$ traps are also, except that they are in the regions of dislocations. (C) 2003 American Institute of Physics.
\end{abstract}

[DOI: $10.1063 / 1.1560562]$

$\mathrm{GaN}$ is an excellent material for fabricating devices, which include heterojunction bipolar transistors, high mobility transistors, and thyristors for high-temperature and highpower applications. Due to GaN's inert chemical nature and high bond energies, it is resistant to most wet chemical etchants, making device patterning mostly dependent on dry etching. Plasma-etching damage has been studied mainly by analyzing current-voltage characteristics of Schottky barrier diodes (SBDs) made on the damaged GaN surface, in conjunction with various etching and annealing conditions. ${ }^{1-3}$ It is believed that the degraded $I-V$ characteristics are associated with etching-induced defects, which, however, have not yet been elucidated. In this work, we use deep-level transient spectroscopy (DLTS) to demonstrate that a well-known trap is strongly enhanced in $n-\mathrm{GaN}$ by plasma etching. An important conclusion is that this trap must be defect related.

The plasma-etching technique used in the study is inductively coupled plasma reactive ion etching (ICP-RIE), using $\mathrm{Cl}_{2} / \mathrm{Ar}$ gas chemistry. From a previous study, the etching bias-voltage used in ICP-RIE was found to be the most significant cause of plasma-etching damage on the surface of $n$-GaN. ${ }^{3}$ In the present study, four unintentionally doped $n$-type GaN samples were grown on sapphire by metalorganic chemical-vapor deposition (MOCVD), with one used as a control sample. Under an ICP coil power of $300 \mathrm{~W}$, chamber pressure of 3 mTorr, and gas flow rate of $15 / 5 \mathrm{sccm}$ of $\mathrm{Cl}_{2} / \mathrm{Ar}$, three samples were plasma-etched for $3 \mathrm{~min}$ at bias voltages of $-50,-100$, and $-150 \mathrm{~V}$, respectively. The sample surface temperature during ICP was estimated to be much less than $100^{\circ} \mathrm{C}$. Before etching, each sample was exposed to a pre-etch plasma cleaning for $20 \mathrm{~s}$ using standard

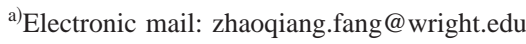

plasma cleaning procedures. Schottky dots of $200 \mu \mathrm{m}$ and large-area ohmic contacts, surrounding the dots, were fabricated on the surface using $\mathrm{Ni}$ and $\mathrm{Ti} / \mathrm{Al} / \mathrm{Ti} / \mathrm{Au}$ metallizations, respectively. A Bio-Rad DL4600 spectrometer with a $100-\mathrm{mV}$ test signal at $1 \mathrm{MHz}$, and a Keithley 617 programmable electrometer were used to take $I-V$, capacitancevoltage $(C-V)$, and DLTS data. The 300-K carrier concentration $\left(n \sim N_{D}-N_{A} \equiv N_{d}\right)$, obtained from $C-V$ data, was used to calculate trap concentrations from the well-known equation $N_{T}=2 N_{d} \Delta C / C$, where $\Delta C$ is the DLTS signal and $C$ the quiescent capacitance at the reverse bias $\left(V_{b}\right)$ used in the measurements. To determine the trap parameters (activation energy $E_{T}$ and capture cross section $\sigma_{n}$ ), DLTS spectra were taken by using rate windows $\left(e_{n}\right)$ ranging from 0.8 to $200 \mathrm{~s}^{-1}$. To indicate the bulk or surface nature of the plasmaetching-induced deep centers, the DLTS spectra were taken using fixed $V_{f}$ and varied $V_{b}$. In this method, the pulse height $V_{f}$ was kept at $+0.5 \mathrm{~V}$, while the $V_{b}$ were varied from -3.5 to $-0.5 \mathrm{~V}$. To determine if the deep traps might be related to "line defects" due to the presence of threading dislocations, ${ }^{4}$ DLTS spectra were measured by varying the filling pulse width $\left(W_{f}\right)$ from 0.2 to $100 \mathrm{~ms}$.

Carrier concentrations in the control and plasma-etched samples, determined by $C-V$ measurements on several SBDs for each sample, are somewhat nonuniform and can be classified into two groups: higher $n\left(\sim 5 \times 10^{16} \mathrm{~cm}^{-3}\right)$ in group I, and lower $n\left(\sim 2 \times 10^{16} \mathrm{~cm}^{-3}\right)$ in group II. All comparisons, presented subsequently, are made among samples in the same group, since similar trends in plasma-etchinginduced changes can be found for samples in a given group. However, there exist systematic differences in the relative densities of observed traps in the two groups; that is, higher trap B and lower trap $E_{1}$ in group $I$ and vice versa in group 


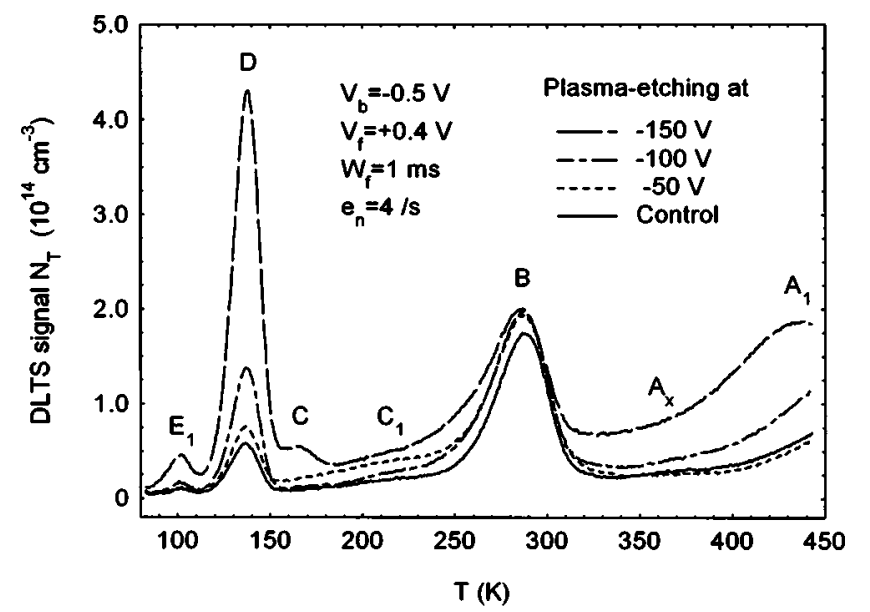

FIG. 1. DLTS spectra for one control and three plasma-etched samples in group II.

II (not shown here). From 300-K $I-V$ characteristics for the group-I samples, ideality factors $(\eta)$, extracted from the forward $I-V$ curves, are very close to unity. However, Schottky barrier heights $\left(\phi_{b}\right)$ were found to reduce from $0.93 \mathrm{eV}$ for the control sample to $0.86 \mathrm{eV}$ for the sample etched at -150 $\mathrm{V}$, which is consistent with the trend of $\phi_{b}$ reduction as a function of etching bias-voltage, as reported in a previous study. ${ }^{3}$ Although reverse currents for the samples are quite low due to background doping levels only in the $10^{16} \mathrm{~cm}^{-3}$ range, they do increase with higher etching bias-voltages. This increase is believed to be associated with defects formed during the plasma etching. DLTS spectra for the group-II samples, measured at a low $V_{b}$ of $-0.5 \mathrm{~V}$ (note that low $V_{b}$ is better for revealing traps at shallow depths), are shown in Fig. 1. In the figure, we find that: (i) there exist at least six traps, $\mathrm{A}_{1}(\sim 0.90-1.0 \mathrm{eV}), \mathrm{A}_{x}(\sim 0.72 \mathrm{eV}), \mathrm{B}(0.61$ $\mathrm{eV}), \mathrm{C}_{1}(0.44 \mathrm{eV}), \mathrm{D}(0.25 \mathrm{eV})$, and $\mathrm{E}_{1}(0.17 \mathrm{eV})$, which can often be observed in GaN layers grown by other techniques; ${ }^{5}$ (ii) in the control sample, $\mathrm{B}$ is dominant and $\mathrm{A}_{1}, \mathrm{D}$, and $\mathrm{E}_{1}$ are observable; (iii) as the etching bias-voltage increases, $\mathrm{D}$ increases, but $\mathrm{B}$ is almost unchanged; and (iv) by plasma etching at $-150 \mathrm{~V}, \mathrm{~A}_{1}, \mathrm{C}(0.34 \mathrm{eV}), \mathrm{D}$, and $\mathrm{E}_{1}$ are significantly enhanced, with $\mathrm{D}$ becoming a dominant trap, having a trap density as high as $8.5 \times 10^{14} \mathrm{~cm}^{-3}$. In order to check whether the enhanced traps are concentrated near the surface, DLTS spectra were taken as a function of $V_{b}$ (keeping $V_{f}$ unchanged) for two plasma-etched samples in group I, as pictured in Fig. 2. For sample 2, etched at $-50 \mathrm{~V}$ [see Fig. 2(a)], the peak heights of all the traps decrease as $V_{b}$ (negative value) is reduced, indicating that they are bulk traps. However, for sample 4, etched at $-150 \mathrm{~V}$ [see Fig. 2(b)], the peak heights of $\mathrm{A}_{1}, \mathrm{C}$, and $\mathrm{E}_{1}$ increase as $V_{b}$ (negative value) is reduced, indicating that they are surface traps, related to damage caused by plasma etching. Using equations developed earlier for characterizing near-surface traps, ${ }^{6}$ trap $\mathrm{B}$ in sample 4 can be shown to be bulk (i.e., extending from the surface to a depth of more than $1500 \AA$ ), while trap $E_{1}$ (surface) is concentrated only in the top $780 \AA$ of the sample. For detailed profiles of these various traps, DLTS spectra should be measured using small increments of $V_{f}$, keeping $V_{b}$ fixed. Such profiling studies, for the control and heavily etched samples, are in progress.
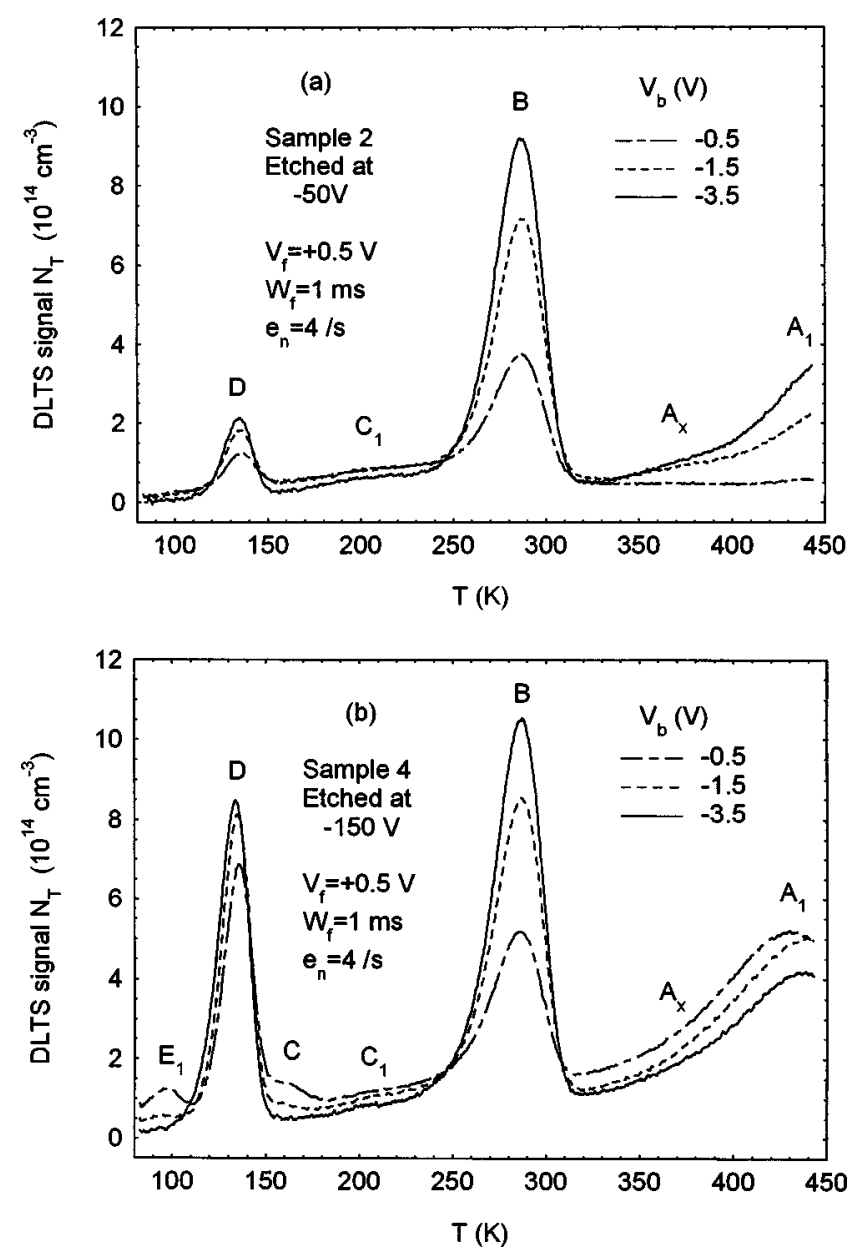

FIG. 2. DLTS spectra measured at different $V_{b}$ for (a) sample 2 and (b) sample 4 in group I.

Because of the high dislocation densities normally found in thin MOCVD GaN samples, we anticipate that many of the traps in such samples will behave as "line defects," as has been found in thin GaN layers grown by other techniques. Based on electron capture kinetics, such line defects have been studied for many traps, including $\mathrm{B}, \mathrm{D}$, and $\mathrm{E}_{1}$, in thin GaN layers grown by molecular beam epitaxy (MBE). ${ }^{4}$ For the four samples in group II, DLTS spectra were measured as a function of $W_{f}$. A typical result, for sample 2, is

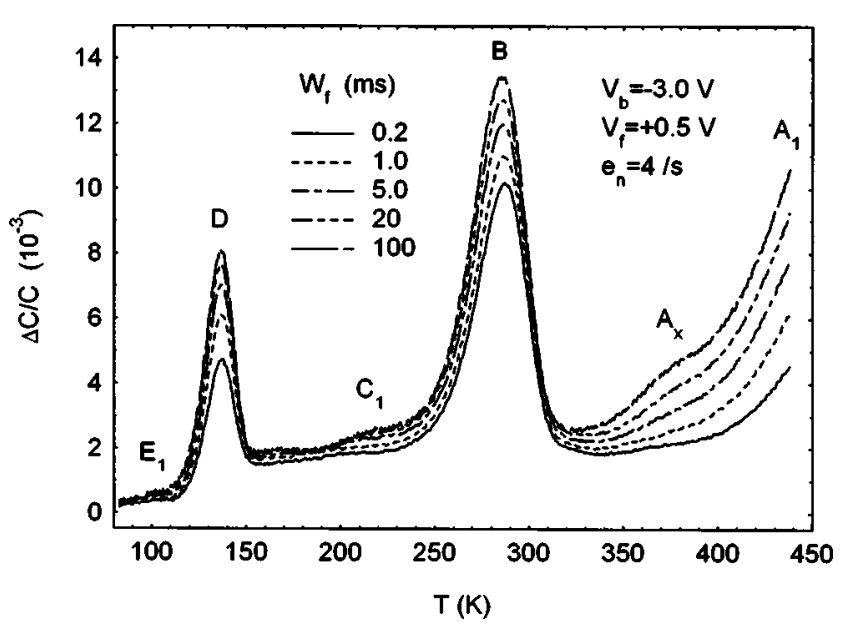

FIG. 3. DLTS spectra, measured using different $W_{f}$, for sample 2 in group II. 


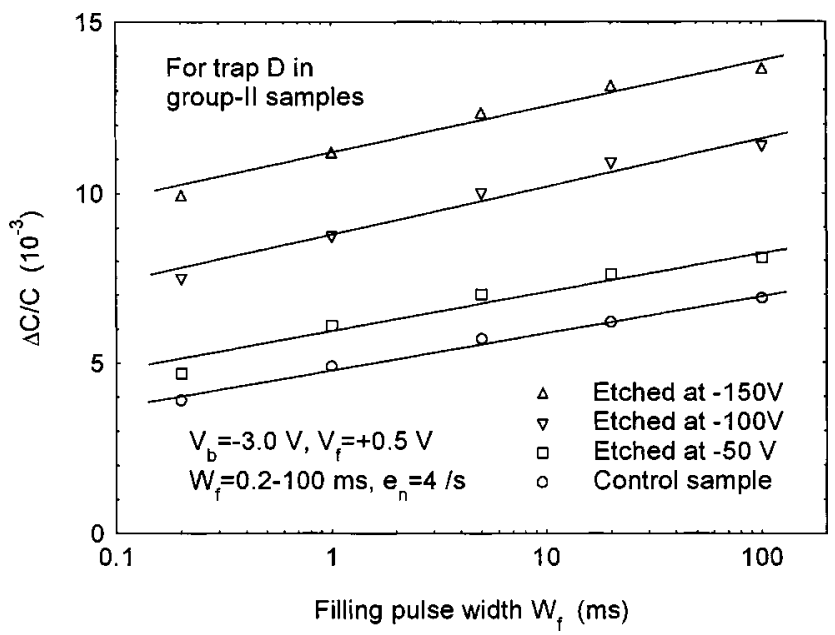

FIG. 4. Logarithmic dependence of DLTS signal on filling pulse width for trap D in group-II samples.

shown in Fig. 3, where we see that the peak heights of the major traps, $A_{1}, B$, and $D$, continually increase with increasing $W_{f}$, up to $100 \mathrm{~ms}$. If the DLTS signals are plotted against logarithmic $W_{f}$, good straight lines can be obtained. Typical results, as exemplified by trap $\mathrm{D}$ in each of the four samples, are presented in Fig. 4. From the figure, we see that: (i) a nearly linear relationship between the DLTS signal $\Delta C / C$ (or $n_{T}$ ) and logarithmic $W_{f}$ holds for trap $\mathrm{D}$ in both the control and plasma-etched samples; and (ii) the slopes for the lines do not change too much, within experimental uncertainty. According to a detailed study by Wosinski ${ }^{7}$ of a dislocation-related electron trap (a line-defect) in plastically deformed $n$-type GaAs crystals, an increase in the slope of the $n_{T}$ versus $\ln \left(W_{f}\right)$ lines means an increase in the density of strain-related dislocations. Therefore, in our case, we believe that the plasma treatments do not cause any meaningful increase in dislocation density, even under an etching biasvoltage of $-150 \mathrm{~V}$. Trap D, with $E_{T}=0.23-0.27 \mathrm{eV}$ and $\sigma_{n}=(1-2) \times 10^{-15} \mathrm{~cm}^{2}$, has been observed in thin $\mathrm{GaN}$ layers by many groups, using various techniques, including hydride vapor phase epitaxy (HPVE),${ }^{8-10}$ MOCVD,${ }^{11-13}$ and MBE. ${ }^{14,15}$ Three of these studies are consistent with the proposition that trap D is at least sometimes related to threading dislocations. For example, the concentration of trap D in HVPE GaN increases with increasing dislocation density, corresponding to decreasing epilayer thickness. ${ }^{9,10}$ Furthermore, the concentration of trap $\mathrm{E}_{1}$ (similar to trap D) in MOCVD GaN increases with increasing concentration of edge dislocations, as measured by the broadening of the (102) Bragg peak as the buffer-layer growth rate is reduced. ${ }^{13}$

We can summarize our major results as follows: (i) trap $\mathrm{D}$ and the other traps are bulk-like in the unetched sample; (ii) trap D is greatly enhanced by plasma-etching at high bias-voltages, but the additional trap- $\mathrm{D}$ concentration is closer to the surface; (iii) traps $\mathrm{A}_{1}, \mathrm{C}$, and $\mathrm{E}_{1}$ are also enhanced in the surface region; and (iv) all of these traps behave as dislocation-related line defects. From previous studies, ${ }^{5,16}$ we have shown that: (i) two DLTS centers, E $(0.18 \mathrm{eV})$ and $\mathrm{A}_{2}(0.90 \mathrm{eV})$ can be induced in MOCVD GaN by $1-\mathrm{MeV}$ electron irradiation (EI); and (ii) the $\mathrm{E}$ center, which actually consists of two components (ED1 and ED2), is related the nitrogen vacancy $\left(V_{N}\right)$, and the $A_{2}$ center might be related to the nitrogen interstitial $\left(\mathrm{N}_{\mathrm{I}}\right)$. In the present study, four deep centers, $A_{1}$ (similar to $A_{2}$ ), C, D, and $E_{1}$ (similar to $E$ ), are significantly enhanced in the surface region of unintentionally-doped MOCVD GaN following ICP-RIE under high etching bias. We believe that all of these centers are basically point defects, although sometimes such defects can be aligned along dislocations. One of the traps, $E_{1}$, might well be related to $V_{N}$, because its activation energy is very close to that of trap E, induced by EI. Trap D, owing to its association with high dislocation density, could be a complex of $\mathrm{V}_{\mathrm{N}}-\mathrm{V}_{\mathrm{Ga}}$, as discussed in Ref. 10. Furthermore, trap $\mathrm{C}$ has been associated with RIE-induced surface damage in free-standing GaN. ${ }^{6}$ It is also possible that trap $\mathrm{A}_{1}$ is related to $\mathrm{N}_{\mathrm{I}}$ as discussed in Ref. 5. The enhancement of $\mathrm{V}_{\mathrm{N}}$-related traps by ICP-RIE, found in this study, is consistent with the observation of a nitrogen-deficient near-surface region in plasma-etched $n$-GaN, studied by Auger electron spectroscopy. ${ }^{1}$ However, to substantiate these defect identifications, further DLTS studies on plasma-etched GaN layers, grown by different techniques and with differing dislocation densities, are needed.

The work of two of the authors (Z.Q.F.) and (D.C.L.) was supported by AFOSR Grant No. F49620-00-1-0347 (monitored by Dr. J. Witt) and ONR Grant N00014-02-10606 (Dr. C. Wood).

${ }^{1}$ A. P. Zhang, G. T. Dang, F. Ren, X. A. Cao, H. Cho, E. S. Lambers, S. J. Pearton, R. J. Shul, L. Zhang, A. G. Baca, R. Hickman, and J. M. Van Hove, J. Electrochem. Soc. 147, 719 (2000).

${ }^{2}$ X. A. Cao, A. P. Zhang, G. T. Dang, F. Ren, S. J. Pearton, R. J. Shul, and L. Zhang, J. Vac. Sci. Technol. A 18, 1144 (2000).

${ }^{3}$ F. A. Khan, L. Zhou, V. Kumar, and I. Adesida, J. Vac. Sci. Technol. B 19, 2926 (2001).

${ }^{4}$ Z.-Q. Fang, D. C. Look, and L. Polenta, J. Phys.: Condens. Matter 14, 13061 (2002).

${ }^{5}$ Z.-Q. Fang, L. Polenta, J. W. Hemsky, and D. C. Look, in the 2000 International Semiconducting and Insulating Materials Conference (SIMC-XI), Canberra, edited by C. Jagadish and N. J. Welham (IEEE, Piscataway, NJ, 2001), p. 35.

${ }^{6}$ D. C. Look and Z.-Q. Fang, Appl. Phys. Lett. 79, 84 (2001).

${ }^{7}$ T. Wosinski, J. Appl. Phys. 65, 1566 (1989).

${ }^{8}$ P. Hacke, T. Detchprohm, K. Hiramatsu, N. Sawaki, K. Tadatomo, and K. Miyake, J. Appl. Phys. 76, 304 (1994).

${ }^{9}$ W. K. Götz, J. Walker, L. T. Romano, N. M. Johnson, and R. J. Molnar, Mater. Res. Soc. Symp. Proc. 449, 525 (1997).

${ }^{10}$ Z.-Q. Fang, D. C. Look, J. Jasinski, M. Benamara, Z. Liliental-Weber, and R. J. Molnar, Appl. Phys. Lett. 78, 332 (2001).

${ }^{11}$ Z.-Q. Fang, J. W. Hemsky, D. C. Look, and M. P. Mack, Appl. Phys. Lett. 72, 448 (1998).

${ }^{12}$ F. D. Auret, S. A. Goodman, F. K. Koschnick, J.-M. Spaeth, B. Beaumont, and P. Gibart, Appl. Phys. Lett. 73, 3745 (1998).

${ }^{13}$ H. K. Cho, K. S. Kim, C.-H. Hong, and H. J. Lee, J. Cryst. Growth 223, 38 (2001)

${ }^{14}$ C. D. Wang, L. S. Yu, S. S. Lau, E. T. Yu, W. Kim, A. E. Botchkarev, and H. Morkoç, Appl. Phys. Lett. 72, 1211 (1998).

${ }^{15}$ Z.-Q. Fang, D. C. Look, W. Kim, Z. Fan, A. Botchkarev, and H. Morkoç, Appl. Phys. Lett. 72, 2277 (1998).

${ }^{16}$ L. Polenta, Z.-Q. Fang, and D. C. Look, Appl. Phys. Lett. 76, 2086 (2000). 